\title{
ORIGINAL ARTICLE \\ Bosentan reduces neuronal apoptosis following spinal cord ischemic reperfusion injury
}

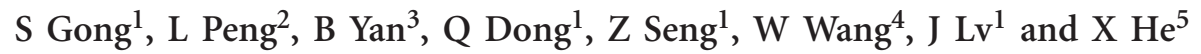

Study design: Experimental study.

Objectives: To investigate the effects of endothelin-receptor antagonist Bosentan on the spinal neural apoptosis in rats with ischemic reperfusion (IR) injury.

Setting: Department of Neurosurgery, the Second Affiliated Hospital, Xi'an Jiaotong University School of Medcine, Xi'an, Shaanxi Province, China

Methods: Sprague-Dawley Rats were randomly divided into two groups, saline (IRS, $n=48$ ) and Bosentan (IRB, $n=48)$ treatment, respectively, when reperfused in $6 \mathrm{~h}, 12 \mathrm{~h}, 24 \mathrm{~h}, 3$ days, 5 days and 7 days. Immunohistochemical staining was used to assess endothelin-1 (ET-1), endothelin receptor type A $\left(E T R_{A}\right)$, endothelin receptor type B $\left(E T R_{B}\right), B c l-2, B a x$, Caspase-8, Caspase-9 and Caspase-3 expression. ET-1 and its receptor in spinal cord tissue were evaluated by real-time PCR. Plasma ET-1 concentration was also detected using radioimmunoassay.

Results: Compared with the group IRS, plasma concentration of ET-1 in group IRB was significantly increased at each time point $(P<0.05)$ and peaked at $24 \mathrm{~h}(P<0.01)$. ETR $\mathrm{B}_{\mathrm{B}}$ expression in group IRB was significantly higher than group IRS at each time point $(P<0.05)$ and peaked at day $3(P<0.01)$. The difference in the expression of ETR $\mathrm{A}_{\mathrm{A}}$ was not statistically significant in the group IRS and IRB $(P>0.05)$. The apoptosis rate in group IRB was significantly decreased at each time point $(P<0.05)$. The protein expressions of $\mathrm{Bcl}-2$, Bax, Caspase- 8 , Caspase- 9 and Caspase-3 were significantly increased in response to Bosentan treatment after IR.

Conclusion: These results suggest Bosentan decreases apoptosis rate after IR injury in the spinal cord, possibly through the ET-1$\mathrm{ETR}_{\mathrm{B}}$ signaling pathway.

Spinal Cord (2014) 52, 181-185; doi:10.1038/sc.2013.133; published online 26 November 2013

Keywords: ischemia reperfusion injury; Bosentan; apoptosis; endothelin; ETR

\section{INTRODUCTION}

Globally, the incidence rate, death rate and age of spinal cord injury may vary, but its complications, high cost and poor prognosis ${ }^{1}$ are common throughout the world. Spinal cord ischemic reperfusion injury (SIRI) is an essential step in secondary injury during the recovery of spinal cord blood flow following thoraco-abdominal aortic surgery. ${ }^{2}$ SIRI can cause various complications such as paraplegia, decubitus and pulmonary infection. ${ }^{3}$ Present studies suggest that the pathophysiological mechanisms underlying SIRI are complicated, including inflammatory factor release, endothelial cell dysfunction and neuronal apoptosis. ${ }^{4}$ Several studies have showed that the mechanism involved in apoptosis includes the upregulation of Akt protein and caspase- 3,5 as well as endoplasmic reticulum stress ${ }^{6}$ in IR neural cells. A series of drugs have been administered in clinics and experiments have been conducted to prevent or treat SIRI. ${ }^{7}$ Endothelin has been shown to have an essentially damaging effect on myocardia ${ }^{8}$ and hepatic ${ }^{9}$ reperfusion injury. Endothelin plays a role through the action of endothelin receptors, which are $G$ protein-coupled receptors, including $\mathrm{ETR}_{\mathrm{A}}$ and $\mathrm{ETR}_{\mathrm{B}}$. There is abundant $\mathrm{ETR}_{\mathrm{A}}$ expression in vascular smooth muscle cells where its activation leads to a long-lasting contraction by eliciting an increase of intracellular calcium. ETR $_{\mathrm{B}}$ is mainly expressed in endothelial cells where it leads to relaxation of vascular smooth muscle cells by inducing the release of nitric oxide, ${ }^{10,11}$ thereby. Bosentan, which is a nonselective endothelin-receptor antagonist, ${ }^{12}$ has been shown to greatly ameliorate the myocardium ${ }^{13}$ and skeletal muscle ${ }^{14}$ injury after IR. However, there is no study on its protective role in SIRI to date. In this study, a rat model of SIRI was established and Bosentan was applied. It was found that Bosentan could reduce neuronal apoptosis following SIRI. Interestingly, endothelin-1 (ET-1) and ETR were significantly upregulated. It has raised the possibility that Bosentan could affect the apoptosis progress via ET-1-ETR signaling pathway. Therefore, it will enhance the understanding of the pathology of SIRI and provide theoretical evidence for future medical management.

\footnotetext{
${ }^{1}$ Department of Neurosurgery, the Second Affiliated Hospital, Xi'an Jiaotong University School of Medicine, Shaanxi Province, China; ${ }^{2}$ Department of Cardiology, the Second Affiliated Hospital, Xi'an Jiaotong University School of Medicine, Shaanxi Province, China; ${ }^{3}$ Department of Emergency Medicine, the Second Affiliated Hospital, Xi'an Jiaotong University School of Medicine, Shaanxi Province, China; ${ }^{4}$ Department of Spine Surgery, Xi'an Red Cross Society Hospital, Xi'an Jiaotong University, Shaanxi Province, China and ${ }^{5}$ Department of Orthopedics, the Second Affiliated Hospital, Xi'an Jiaotong University School of Medicine, Shaanxi Province, China

Correspondence: Professor S Gong, Department of Neurosurgery, the Second Affiliated Hospital, Xi'an Jiaotong University School of Medicine, Shaanxi Province, 710004, China. E-mail: shpingg@126.com.

or Professor X He, Department of Orthopedics, the Second Affiliated Hospital, Xi'an Jiaotong University School of Medicine, Shaanxi Province 710004, China.

E-mail: xijing_h@vip.tom.com
}

Received 15 June 2013; revised 30 September 2013; accepted 12 October 2013; published online 26 November 2013 


\section{MATERIALS AND METHODS}

\section{Experimental animals and grouping}

A total of 96 male Spraque-Dawley rats weighing between 250 and $300 \mathrm{~g}$ were purchased from the Animal Center of Xi'an Jiaotong University, China. Animals were randomly divided into IR + saline (IRS, $n=48$ ) and the IR + Bosentan (IRB, $n=48$ ). Group IRS and IRB were divided into another six groups, according to reperfusion times: $6 \mathrm{~h}, 12 \mathrm{~h}, 24 \mathrm{~h}, 3$ days, 5 days and 7 days. Group IRB was injected with Bosentan (Actelion Pharmaceuticals Ltd., Allschwil, Switzerland, $5 \mathrm{mg} \mathrm{kg}^{-1}$ body weight) via the caudal vein at $20 \mathrm{~min}$ prior to reperfusion, followed by caudal vein injection with an equal dose of Bosentan at $24 \mathrm{~h}$ intervals until killed. Group IRS was injected with an equal dose of saline via the caudal vein at each time point. ${ }^{13}$

\section{Establishment of rat models of SIRI, serum and spinal cord specimen collection}

After fasting $12 \mathrm{~h}$ before surgery, the rats were intraperitoneally anesthetized with $0.75 \%$ amobarbital sodium $\left(4 \mathrm{ml} \mathrm{kg}^{-1}\right)$. Ischemia of the lumbar spinal cord was induced by clamping the abdominal aorta with a mini aneurysm clamp for $60 \mathrm{~min}$, followed by $6 \mathrm{~h}, 12 \mathrm{~h}, 24 \mathrm{~h}, 3$ days, 5 days and 7 days of reperfusion. ${ }^{15}$ The occlusion sites were approximately $0.5 \mathrm{~cm}$ below the left and just proximal to the aortic bifurcation. Sham operation rats underwent the same operative procedure with the exception of aortic occlusion. Blood samples $(2 \mathrm{ml})$ were collected from the inferior vena cava and stored in an additional tube containing $7.5 \%$ disodium ethylenediamine tetra-acetic acid $(30 \mu \mathrm{l})$ and aprotinin $(40 \mu \mathrm{l}$; blood volume could be increased or decreased according to proportion), then centrifuged at 3000 r.p.m. for $10 \mathrm{~min}$ at $4{ }^{\circ} \mathrm{C}$. Plasma was separated and stored at $-70^{\circ} \mathrm{C}$. After reperfusion, the rats in each group were anesthetized. A median incision was made on the back, and the vertebral plate was opened to expose $\mathrm{L}_{2}-\mathrm{L}_{5}$ spinal cord. $\mathrm{L}_{3}$ spinal cord was dissociated and obtained for future analysis.

Plasma ET-1 content was determined using radioimmunoassay. In accordance with instructions for the ${ }^{125} \mathrm{I}$ endothelin radioimmunoassay kit (General Hospital of Chinese PLA, Beijing, China), plasma was measured and standard curves were drawn. ET-1 concentrations were calculated. ${ }^{16}$

Immunohistochemical staining for ET-1, ETR ${ }_{A}, E_{B}, B c l-2, B a x$, Caspase-8, Caspase- 9 and Caspase- 3 expression

Transverse sections $4 \mu \mathrm{m}$ thick were cut and mounted on glass slides treated with silica after paraffin embedding. The slides were deparaffinized with graded concentrations of xylene and ethanol. Tissue sections were treated with block serum for $30 \mathrm{~min}$ at room temperature to block non-specific binding sites. Thereafter, the sections were incubated with antibodies against ET-1 (1:200 dilution, rabbit polyclonal, Abcam, Cambridge, MA, USA), ETR (1:50 dilution, rabbit polyclonal, Millipore, Billerica, MA, USA), $\operatorname{ETR}_{B}(1: 50$ dilution, rabbit polyclonal, Millipore), and Bcl-2, Bax, Caspase-8, Caspase-9, Caspase-3 (1:50 dilution, rabbit polyclonal, Thermo Scientific, Germaring, Germany) at $4{ }^{\circ} \mathrm{C}$ overnight. Specimens were incubated with secondary antibody and horseradish peroxidase complex solution in accordance with instructions given in the immunohistochemical staining kit (Beijing Biosynthesis Biotechnology Co., Ltd., Beijing, China). Samples were then developed with 3, 3'-diaminobenzidine (Beijing Biosynthesis Biotechnology Co., Ltd.), and mounted onto slides. Sections were then imaged, analyzed and observed by another investigator, who was not familiar with the study design. Five sections of each rat from each group were made. Five different vision fields of a section were analyzed by an image analysis collection system (Q553Cw; Leica, Wetzlar, Germany) and the average optical densities (grey value) were measured. Gray value is inversely proportional to the protein expression in our analysis system.

\section{Quantitative real-time PCR for ET-1 and its receptor in spinal cord tissue}

The mRNA was extracted and reverse transcribed to cDNA with a Geneamp PCR System 9700 (Applied Biosystems, Foster, CA, USA) in accordance with RevertAid First Strand cDNA Synthesis Kit \#K1622 (Fermentas, Vilnius, Lithuania). DNA was amplified with corresponding primers using $2 \mu \mathrm{l}$ of reverse transcription solution as a template. PCR was conducted on an ABI Prism 7000 Sequence Detection System (Applied Biosystems, Foster, CA, USA). With a SYBR Green Real-time PCR Master Mix kit (TOYOBO, Osaka, Japan), total reaction volume was $25 \mu$ l. Parallel wells were used for all specimens and $\beta$-actin was utilized as internal reference. Primer design (Aoke Biotechnology, Beijing, China) is as follows: $\beta$-actin: forward, $5^{\prime}$-TCACCCACACTgTgCCCATCTATgA-3' ${ }^{\prime}$, reverse, $5^{\prime}$-CATCggAACCgCTCATTgCCg ATAg$3^{\prime}$; ET-1: forward, $5^{\prime}$-gTT gCT CCT gCT CCT CCT TG-3', reverse, $5^{\prime}$-ACT ggC ATC TgT TCC CTT gC-3'; ETR $_{\mathrm{A}}$ : forward, $5^{\prime}$-gCT CAA CgC CAC gAC CAA G $-3^{\prime}$, reverse, $5^{\prime}$-gTg TTC gCT gAg ggC AAT CC-3'; $\mathrm{ETR}_{\mathrm{B}}$ : forward, $5^{\prime}$-ggC CAA gAC AgT ATT CTg CCT-3'; reverse, 5' -ACC AgC AgC ACA AAC ACg ACT-3' The outcome of PCR was assessed using the $2^{-\Delta \Delta \mathrm{Ct}}$ method. ${ }^{16}$

\section{Terminal deoxyribonucleotidyl transferse (TdT)-mediated biotin-16-dUTP nick-end labeling (TUNEL) assay}

Paraffin sections were prepared as for hematoxylin-eosin staining. Sections were dewaxed and hydrated. In accordance with instructions given for the TUNEL kit (Promega, Madison, WI, USA), cells were quantified under a $40 \times$ microscope (Q553Cw; Leica). Five visual fields of tissue were randomly selected. The number of TUNEL-positive cells was separately quantified for every 50 cells in the field. Apoptotic index was calculated by the following formula: the number of apoptotic cells/total number of cells $\times 100 \% .{ }^{17}$

\section{Statistical analysis}

The data was analyzed using SPSS 17.0 for Windows (Chicago, IL, USA). The results were expressed as the mean \pm standard error. Comparisons between groups were performed with Kruskal-Wallis analysis of variance and One-Way Anova. For all analyses, statistical significance was defined at $P<0.05$.

We certify that all applicable institutional and governmental regulations concerning the ethical use of animals were followed during the course of this research.

\section{RESULTS}

The treatment of Bosentan after IR increased the expression of ET-1 Compared with the group IRS, protein expression of plasma ET-1 in group IRB significantly increased at each time point $(P<0.05)$ and peaked at $24 \mathrm{~h}$ (Figure 1c). Gray value is inversely proportional to the protein expression in our analysis system. Protein and mRNA expression of ET-1 were also significantly increased and peaked at same time point in group IRB (Figures $1 \mathrm{a}, \mathrm{b}$ and $\mathrm{d}$ ).

\section{Bosentan increased $\mathrm{ETR}_{\mathrm{B}}$ expression following IR}

Gray value is inversely proportional to the protein expression in our analysis system. Protein expression of $\mathrm{ETR}_{\mathrm{B}}$ in group IRB was significantly higher than group IRS at each time point $(P<0.05)$ (Figures $2 \mathrm{a}$ and $\mathrm{b}$ ) and peaked at day 3 (Figure $2 \mathrm{~b}$ ). Compared with the group IRS, mRNA expression of $\mathrm{ETR}_{\mathrm{B}}$ was also significantly increased $(P<0.05)$ and peaked at $24 \mathrm{~h}$ (Figure $2 \mathrm{c}$ ).

\section{Bosentan had no effect on $\mathrm{ETR}_{\mathrm{A}}$ expression following IR} $\mathrm{ETR}_{\mathrm{A}}$ was only expressed in astrocytes (Figure 3a), and there was no statistically significant difference in the protein and mRNA expression of $\mathrm{ETR}_{\mathrm{A}}$ in the group IRS and IRB $(P>0.05)$ (Figures $3 \mathrm{~b}$ and $\mathrm{c}$ ).

The treatment of Bosentan decreased cell apoptosis induced by IR Compared with the group IRS, the proportion of apoptotic cells in group IRB significantly decreased at each time point $(P<0.05)$ (Figure 4a). Gray value is inversely proportional to the protein expression in our analysis system. The protein expressions of Bcl-2, Bax, Caspase- 8 , Caspase- 9 and Caspase- 3 were significantly decreased in response to Bosentan treatment after IR (Figures $4 \mathrm{~b}-\mathrm{e}$ ). 
a
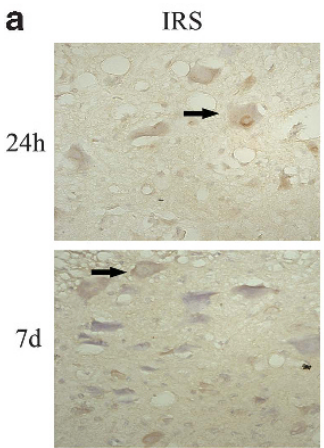

C

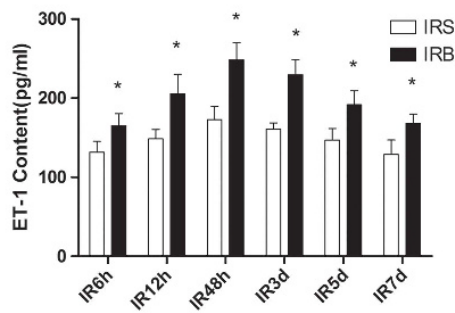

IRB
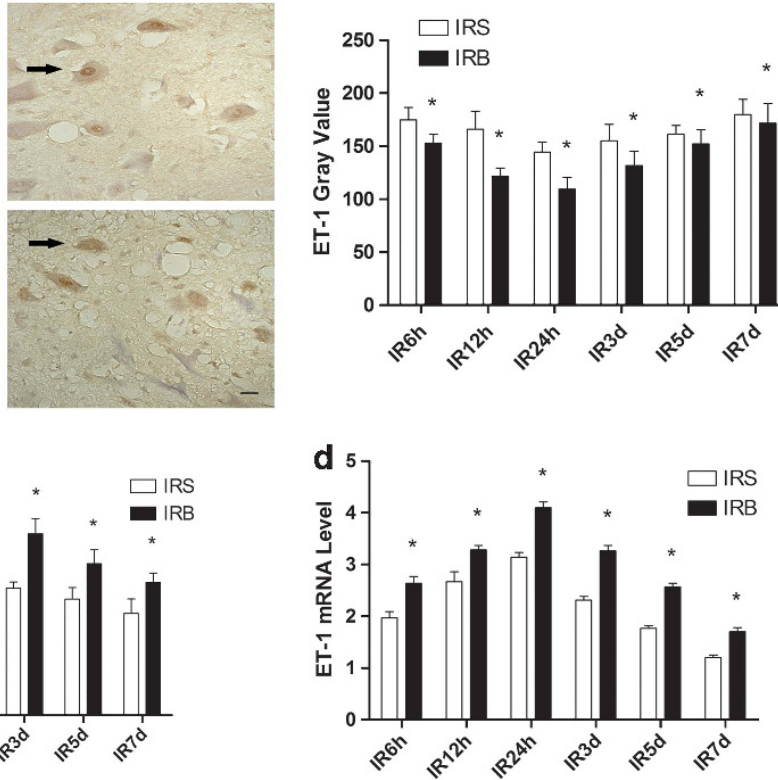

b

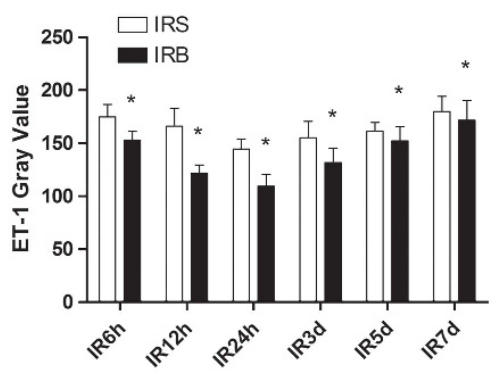

Figure 1 The expression of ET-1 following the treatment of Bosentan after IR. (a) Immunohistochemistry showing ET-1 expression prior to and following Bosentan intervention $(\times 400)$. Black arrows indicate ET-1 expression cells. IR, ischemic reperfusion; IRS, IR + saline group; IRB, IR + Bosentan group; $24 \mathrm{~h}$ or $7 \mathrm{~d}$, reperfusion $24 \mathrm{~h}$ or 7 days. (b) Histogram revealing the changes in gray values of ET-1 in neural cells of the anterior horn of the spinal cord following Bosentan intervention. The stronger expression exhibited a lower gray value. ${ }^{*} P<0.05$ vs IRS group. (c) Changes in ET-1 plasma content following Bosentan intervention $\left(\bar{x} \pm \mathrm{S}, \mathrm{pg} \mathrm{ml}^{-1}\right)$. ${ }^{*} P<0.05$ vs IRS group. (d) Histogram demonstrating the changes in ET-1 mRNA levels in spinal cord tissue following IR and Bosentan intervention. Representative images from four rats in each group are presented here. Scale bar: 100 um.

a
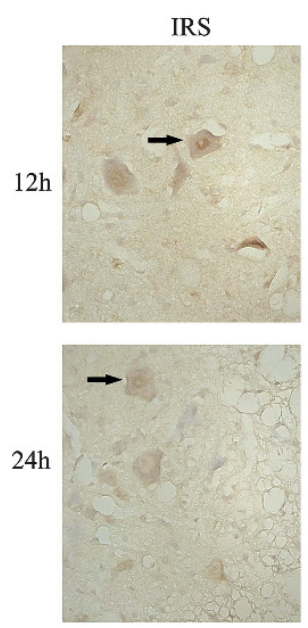

IRB
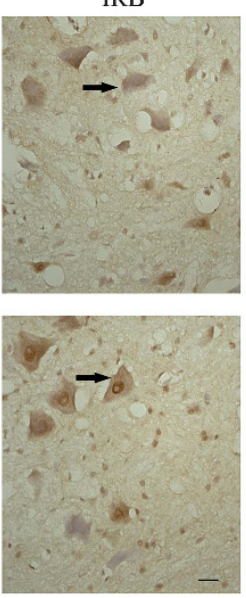
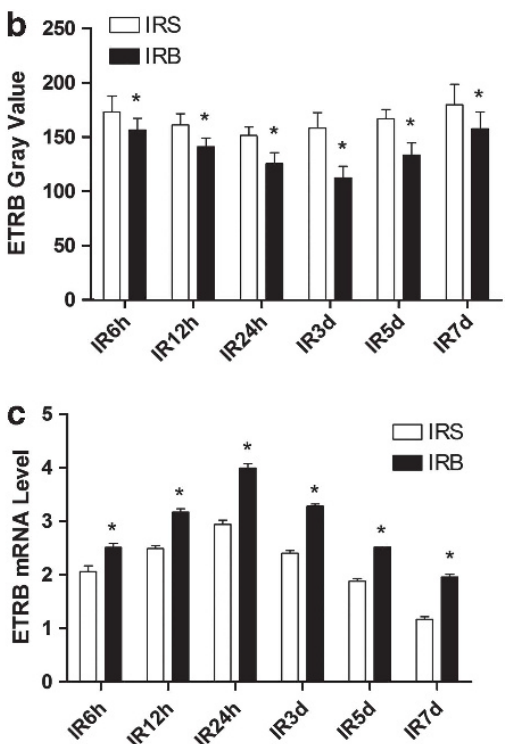

Figure 2 The expression of $\mathrm{ETR}_{\mathrm{B}}$ following the treatment of Bosentan after IR. (a) Immunohistochemistry showing ETR $\mathrm{B}_{\mathrm{B}}$ expression in spinal cord tissue from each group $(\times 400)$. Black arrows indicate $E^{2} R_{B}$ expression cells. IR, ischemic reperfusion; IRS, IR + saline group; IRB, IR+Bosentan group; 12 or $24 \mathrm{~h}$, reperfusion 12 or $24 \mathrm{~h}$. (b) Histogram showing the changes in gray values of ETR $\mathrm{B}_{B}$ in neural cells of the anterior horn of the spinal cord following Bosentan intervention. Strong protein expression exhibited a low gray value. ${ }^{*} P<0.05$ vs IRS group. (c) Histogram showing the changes in ETR $\mathrm{BRNA}_{\mathrm{B}}$ levels in spinal cord tissue following IR and Bosentan intervention. ${ }^{*} P<0.05$ vs IRS group. Representative images from four rats in each group are presented here. Scale bar: $100 \mu \mathrm{m}$.

\section{DISCUSSION}

In this study, we found that the administration of Bosentan after IR significantly increased expression of ET-1 and ETR $\mathrm{E}_{\mathrm{B}}$. The proportion of apoptotic cells and gene in group IRB significantly decreased following the treatment with Bosentan.
Endothelin has three isoforms (identified as ET-1, -2, -3) and binds to the $\mathrm{ETR}_{\mathrm{A}}$ and $\mathrm{ETR}_{\mathrm{B}} \cdot{ }^{18}$ Endothelin and its receptors have essential pathophysiological effects during myocardial IR injury, ${ }^{8}$ but few studies have investigated their effects on the central nervous system, especially during SIRI. Endothelin induces contraction by acting on 
a
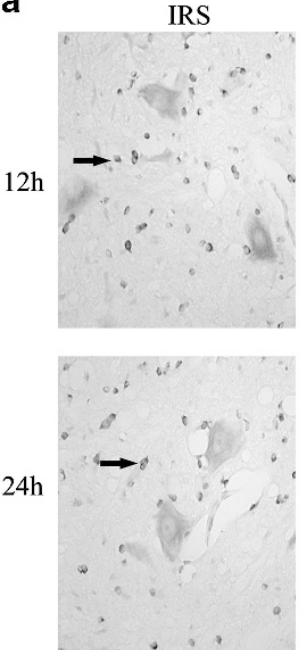

IRB
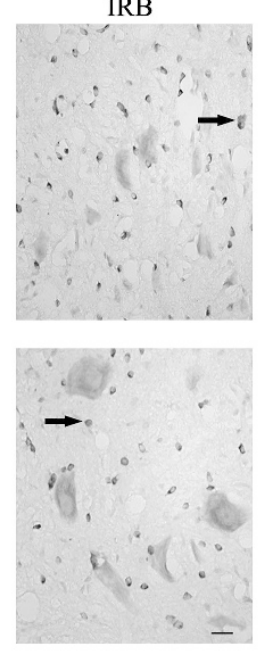
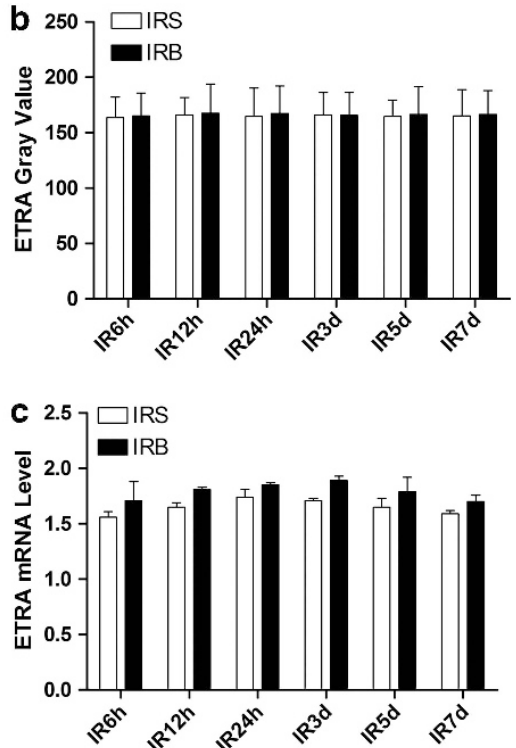

Figure 3 The expression of $\mathrm{ETR}_{\mathrm{A}}$ following the treatment of Bosentan after IR. (a) Immunohistochemistry showing ETR $\mathrm{R}_{\mathrm{A}}$ expression in spinal cord tissue from each group $(\times 400)$. Black arrows indicate $E_{T R}$ expression cells. IR, ischemic reperfusion; IRS, IR + saline group; IRB, IR + Bosentan group; 12 or $24 \mathrm{~h}$, reperfusion 12 or $24 \mathrm{~h}$. (b) Histogram showing the changes in gray values of $E_{T R}$ in astrocytes of the anterior horn of the spinal cord following Bosentan intervention. (c) Histogram showing the changes in ETR $\mathrm{ARNA}$ levels in spinal cord tissue following IR and Bosentan intervention. Representative images from four rats in each group are presented here. Scale bar: $100 \mathrm{um}$.
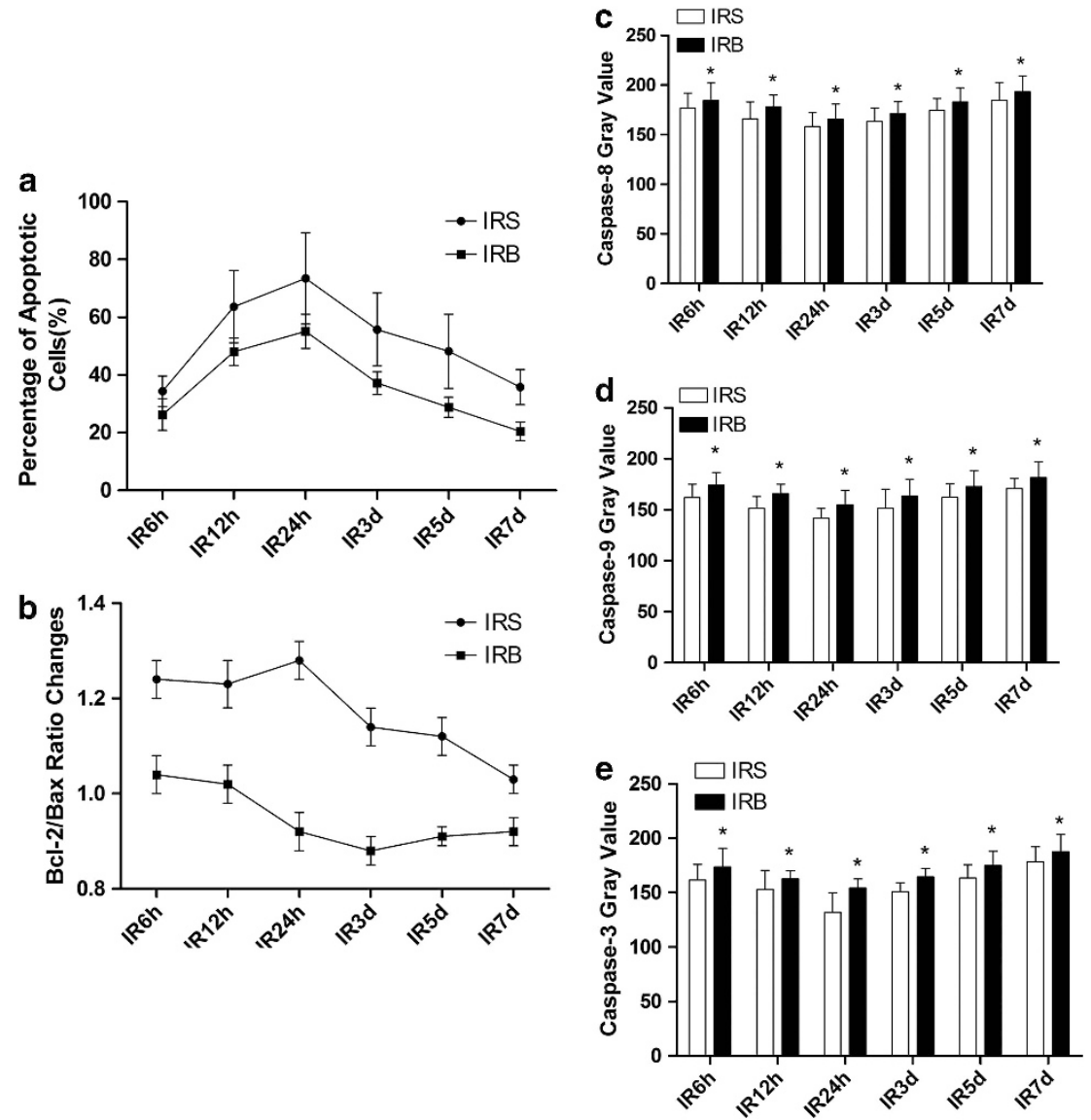

Figure 4 Cell apoptosis induced by IR after the treatment of Bosentan. (a) Histogram showing changes in the percentage of apoptotic cells in the anterior horn of the spinal cord following Bosentan intervention. IR, ischemic reperfusion; IRS, IR + saline group; IRB, IR + Bosentan group; ${ }^{*} P<0.05$ vs IRS group. (b) The Bcl-2/Bax ratio changes in neural cells of the anterior horn of the spinal cord following Bosentan intervention. ${ }^{*} P<0.05$ vs IRS group. (c-e) The gray value changes in Caspase-8, Caspase- 9 and Caspase- 3 in neural cells of the anterior horn of the spinal cord following IR. Strong protein expression exhibited a low gray value. ${ }^{*}<0.05$ vs IRS group. 
$\mathrm{ETR}_{\mathrm{A}}$ and causes vasodilatation and endothelin scavenging by acting on $\mathrm{ETR}_{\mathrm{B}}$ in vascular endothelial cells. ${ }^{19,20}$

Bosentan, a nonselective $\mathrm{ETR}_{\mathrm{A}}$ and $\mathrm{ETR}_{\mathrm{B}}$ antagonist, blocks the biological effects of ET-1 and is approved by the Food and Drug Administration for use as an oral medication for the treatment of pulmonary hypertension. ${ }^{21}$ Results from the present study suggested that plasma and tissue endothelin increased following Bosentan intervention, along with an increase in endothelin mRNA. The possible mechanism is that $\mathrm{ETR}_{\mathrm{B}}$ blockage reduced ET-1 internalization. A previous study confirmed that ET-1 exerts its biological effect by autocrine and paracrine action, resulting in induction of self-expression. ${ }^{22}$ Differences in animal models, species and tissue specificity may also play a role in these various findings.

Our experiment confirmed that $\mathrm{ETR}_{\mathrm{B}}$ expression significantly increased in neuronal cytoplasm, nuclei and glial cells following IR and after Bosentan intervention, which varies from precious studies. ${ }^{23}$ Prior studies demonstrated that under normal conditions, using immunofluorescence, $\mathrm{ETR}_{\mathrm{A}}$ expression was mainly visible in vascular endothelial cells and primary afferent nerve fibers, but $\mathrm{ETR}_{\mathrm{B}}$ expression was mainly detectable in radial glial cells as well as astrocytes, ependymal cells, vascular endothelial cells and smooth muscle cells in the gray matter and white matter. Stenman et al. ${ }^{16}$ indicated that $\mathrm{ETR}_{\mathrm{B}}$ expression obviously increased in a rat model of cerebral ischemia/reperfusion at a transcriptional level, which was associated with inflammatory factors acting on DNA regulatory element. The current study verified that $\mathrm{ETR}_{\mathrm{B}}$ expression increased following Bosentan intervention at a transcriptional level. Whether increased endothelin expression upregulated $\mathrm{ETR}_{\mathrm{B}}$ expression via an unknown pathway requires further investigations.

Cell apoptosis is promoted when the BAX/BAX ratio is greater than the $\mathrm{Bcl}-2 / \mathrm{BAX}$ ratio. When $\mathrm{Bcl}-2$ expression increased, cell death is suppressed. ${ }^{24} \mathrm{BAX}$ and $\mathrm{Bcl}-2$ form a complex, which cannot alter the permeability of the mitochondrial membrane or induce cell apoptosis. Cytochrome $\mathrm{C}$ bound to apoptotic protease activating factor-1, results in apoptotic protease activating factor-1 oligomerization, which is a prerequisite for procaspase- 9 activation. ${ }^{25}$ Subsequently, caspase-3, caspase-7 and caspase- 6 were activated. ${ }^{25}$ In this study, Bcl-2 expression increased following Bosentan intervention, whereas Caspase-8 expression, involved in the death receptor pathway, decreased. These results indicated that Bosentan could protect the spinal cord by affecting the expression of apoptotic proteins. To verify this effect, TUNEL staining was utilized to detect apoptotic cells in tissue sections by measuring nuclear DNA fragments, with a high sensitivity and specificity. ${ }^{26}$ In the current study, the proportion of apoptotic neurons in the spinal cord was remarkably decreased following treatment with Bosentan. The molecular mechanisms of the apoptosis-protecting effect achieved by Bosentan in spinal cord ischemia reperfusion need be evaluated in further studies. Our other study showed that Bosentan upregulated VEGF expression in blood and tissue, which can promote angiogenesis and may be the reason of the apoptosis-protecting effect in spinal cord ischemia reperfusion (unpublished data).

\section{CONCLUSIONS}

This study showed that Bosentan decreased apoptosis rate after IR injury of the spinal cord in a rat SIRI model, possibly through the ET$1-\mathrm{ETR}_{\mathrm{B}}$ signaling pathway.

\section{DATA ARCHIVING}

There were no data to deposit.

\section{CONFLICT OF INTEREST}

The authors declare no conflict of interest.

\section{ACKNOWLEDGEMENTS}

The Natural Science Foundation of China (Surface projects, grant number 81271339) and Sci-Tech Research and Development Program of Shaanxi Province (grant number 2008K13-03(6)) contributed to this research.

1 Chiu WT, Lin HC, Lam C, Chu SF, Chiang YH, Tsai SH. Review paper: epidemiology of traumatic spinal cord injury: comparisons between developed and developing countries. Asia Pac J Public Health 2010; 22: 9-18.

2 Svensson LG, Von Ritter CM, Groeneveld HT, Rickards ES, Hunter SJ, Robinson MF et al. Cross-clamping of the thoracic aorta. Influence of aortic shunts, laminectomy, papaverine, calcium channel blocker, allopurinol, and superoxide dismutase dismutase on spinal cord blood flow and paraplegia in baboons. Ann Surg 1986; 204: 38-47.

3 Juvonen T, Biancari F, Rimpilainen J, Satta J, Rainio P, Kiviluoma K. Strategies for spinal cord protection during descending thoracic and thoracoabdominal aortic surgery: Up-to-date experimental and clinical results_a review. Scand Cardiovasc J 2002; 36: $136-160$.

4 Nishizawa Y. Glutamate release and neuronal damage in ischemia. Life Sci 2001; 69: 369-381.

5 Sakurai M, Nagata T, Abe K, Horinouchi T, Itoyama Y, Tabayashi K. Survival and deathpromoting events after transient spinal cord ischemia in rabbits: induction of Akt and caspase3 in motor neurons. J Thorac Cardiovasc Surg 2003; 125: 370-377.

6 Sakurai M, Takahashi G, Abe K, Horinouchi T, Itoyama Y, Tabayashi K. Endoplasmic reticulum stress induced in motor neurons by transient spinal cord ischemia in rabbits. J Thorac Cardiovasc Surg 2005; 130: 640-645.

7 Rossignol S, Schwab M, Schwartz M, Fehlings MG. Spinal cord injury: time to move? J Neurosci 2007; 27: 11782-11792.

8 Pernow J, Wang QD. Endothelin in myocardial ischaemia and reperfusion. Cardiovasc Res 1997; 33: 518-526.

9 Serracino-Inglott F, Habib NA, Mathie RT. Hepatic ischemia-reperfusion injury. Am J Surg 2001; 181: 160-166.

10 Maxwell MJ, Goldie RG, Henry PJ. Ca2 + signalling by endothelin receptors in rat and human cultured airway smooth muscle cells. Br J Pharmacol 1998; 125: 1768-1778.

11 Tirapelli CR, Casolari DA, Yogi A, Montezano AC, Tostes RC, Legros E et al. Functional characterization and expression of endothelin receptors in rat carotid artery: involvement of nitric oxide, a vasodilator prostanoid and the opening of $\mathrm{K}+$ channels in ETBinduced relaxation. Br J Pharmacol 2005; 146: 903-912.

12 Chin K, Channick R. Bosentan. Expert Rev Cardiovasc Ther 2004; 2: 175-182.

13 Singh AD, Amit S, Kumar OS, Rajan M, Mukesh N. Cardioprotective effects of bosentan, a mixed endothelin type $\mathrm{A}$ and $\mathrm{B}$ receptor antagonist, during myocardial ischaemia and reperfusion in rats. Basic Clin Pharmacol Toxicol 2006; 98: 604-610.

14 Herbert KJ, Hickey MJ, Lepore DA, Knight KR, Morrison WA, Stewart AG. Effects of the endothelin receptor antagonist Bosentan on ischaemia/reperfusion injury in rat skeletal muscle. Eur J Pharmacol 2001; 424: 59-67.

15 Zivin JA, DeGirolami U. Spinal cord infarction: a highly reproducible stroke model. Stroke 1980; 11: 200-202.

16 Stenman E, Malmsjo M, Uddman E, Gido G, Wieloch T, Edvinsson L. Cerebral ischemia upregulates vascular endothelin ET(B) receptors in rat. Stroke 2002; 33: 2311-2316.

17 Li Y, Chopp M, Powers C, Jiang N. Apoptosis and protein expression after focal cerebral ischemia in rat. Brain Res 1997; 765: 301-312.

18 Yanagisawa M, Kurihara H, Kimura S, Tomobe Y, Kobayashi M, Mitsui Y et al. A novel potent vasoconstrictor peptide produced by vascular endothelial cells. Nature 1988; 332: 411-415.

19 Rodriguez-Pascual F, Busnadiego O, Lagares D, Lamas S. Role of endothelin in the cardiovascular system. Pharmacol Res 2011; 63: 463-472.

20 Ekelund U, Adner M, Edvinsson L, Mellander S. Effects of selective ETB-receptor stimulation on arterial, venous and capillary functions in cat skeletal muscle. Br J Clin Pharmacol 1994; 112: 887-894.

21 Cohen $\mathrm{H}$, Chahine $\mathrm{C}$, Hui A, Mukherji R. Bosentan therapy for pulmonary arterial hypertension. Am J Health Syst Pharm 2004; 61: 1107-1119.

22 Hahn AW, Resink TJ, Scott-Burden T, Powell J, Dohi Y, Buhler FR. Stimulation of endothelin mRNA and secretion in rat vascular smooth muscle cells: a novel autocrine function. Cell Regul 1990; 1: 649-659.

23 Peters CM, Rogers SD, Pomonis JD, Egnaczyk GF, Keyser CP, Schmidt JA et al. Endothelin receptor expression in the normal and injured spinal cord: potential involvement in injury-induced ischemia and gliosis. Exp Neurol 2003; 180: 1-13.

24 Korsmeyer SJ. BCL-2 gene family and the regulation of programmed cell death. Cancer Res 1999; 59(7 Suppl), 1693s-1700ss.

25 Dlamini Z, Mbita Z, Zungu M. Genealogy, expression, and molecular mechanisms in apoptosis. Pharmacol Ther 2004; 101: 1-15.

26 Perry SW, Epstein LG, Gelbard HA. Simultaneous in situ detection of apoptosis and necrosis in monolayer cultures by TUNEL and trypan blue staining. BioTechniques 1997; 22: 1102-1106 